\title{
Prospective Memory after Stroke: A Scoping Review
}

Christy Hogan, School of Applied Psychology and Menzies Health Institute Queensland, Griffith University

Associate Professor Jennifer Fleming, School of Health and Rehabilitation Sciences, the University of Queensland and Occupational Therapy Department, Princess Alexandra Hospital

Dr. Petrea Cornwell, School of Applied Psychology and Menzies Health Institute Queensland, and The Prince Charles Hospital Metro North Hospital and Health Service Professor David Shum*, Menzies Health Institute Queensland and School of Applied Psychology, Griffith University 


\begin{abstract}
The aim of this paper was to review the limited, but growing, literature on prospective memory (PM) following stroke using a scoping study methodology. Multiple databases were systematically searched and yielded 11 studies that were classified as observational $(n=7)$ or intervention studies $(n=4)$ and reviewed for quality. PM impairment after stroke was more commonly identified using behavioural measures compared to self-report measures. There were mixed findings regarding the extent and nature of PM impairment post-stroke, however more studies reported impairment for time-based PM, compared to both event- and activity-based PM. Studies examining rehabilitative techniques for PM resulted in mixed findings and were limited as most were case-studies of poor methodological quality. Overall previous research in this area was limited as most studies were often underpowered due to small sample sizes, or used single-item measures which may not be robust enough to reliably measure PM impairment. Additionally, the methods used to measure PM were varied and many studies did not control for retrospective memory impairment, which could impact the results, as PM has both a retrospective (remembering both the action and when it needs to be completed) and prospective component (remembering to perform the action when appropriate). In conclusion, PM impairment is apparent post-stroke, specifically for time-based PM. However, more research is needed to determine why PM impairment occurs, and how it can be improved.
\end{abstract}


Key Words

Brain injury

Stroke

Prospective memory

Memory

Rehabilitation

Scoping Review 


\section{Prospective Memory after Stroke: A Scoping Review}

\section{Introduction}

Stroke can be broadly defined as the sudden onset of neurological symptoms due to a disruption in blood supply to the brain, often resulting in tissue death (Australian Institue of Health and Welfare, 2013; Kolb \& Whishaw, 2009). According to the World Health Organisation (2004), 15 million people worldwide suffer a stroke each year. Of these, 5 million do not survive and another 5 million are left permanently disabled. Dependent on the size and location of infarction or haemorrhage, stroke often causes impairments in a range of physical, communication, behavioural and cognitive functions, which can impact on an individual's daily functioning and ability to live independently (Caplan, 2006; Lincoln, Kneebone, \& Macniven, 2012).

Individuals who have had a stroke are often left with apparent physical and language impairments, and rehabilitation in general aims at using restorative and/or compensatory strategies to treat these. Cognitive impairments are also common after stroke and can influence daily functioning (Caplan, 2006). These include impairment of attention and executive functioning, specifically in the areas of planning, integration of actions, judgement, and the performance of complex behaviours (i.e. integrating behaviours together to cook a complex meal; Andrews, Halford, Chappell, Maujean, \& Shum, 2014; Ownsworth \& Shum, 2008). People with stroke and their families also commonly report impairments in general memory function post-stroke (Andrews, Halford, Shum, et al., 2014; De Haan, Nys, \& Van Zandvoort, 2006; Kalashnikova, Zueva, Pugacheva, \& Korsakova, 2005). The previous literature has often focused on Retrospective 
Memory (RM) or the recall of previously learnt information, rather than another type termed Prospective Memory (PM).

Research focusing on PM is relatively new compared to other forms of memory (i.e. retrospective and working memory), only gaining interest in the experimental and clinical literature in the last 20 to 30 years (Kliegel, McDaniel, \& Einstein, 2008). PM is defined as the encoding, storage, and delayed retrieval of intended actions (Shum, Levin, \& Chan, 2011). Furthermore, PM encapsulates an interaction of multiple cognitive processes, broken down into five stages: (a) intention formation; (b) intention retention; (c) intention initiation; (d) intention execution; and (e) evaluation of outcomes (Ellis \& Milne, 1996). If any of these stages are compromised, PM failure could occur.

PM is considered to have both a retrospective and prospective component (Einstein, McDaniel, Richardson, Guynn, \& Cufner, 1995). The retrospective component is remembering both the action and the time that the action needs to be performed, whereas the prospective component is remembering to perform the action when it is either the appropriate time or when an appropriate event has occurred. Thus, retrospective memory is important for PM performance because if an individual can remember that they had to do something (prospective component) but not remember what it was (retrospective component), a PM failure could still occur.

Three types of PM task have been outlined within the literature: time-, event-, and activity-based. Time-based tasks include those that require an action to be completed at a certain time, or after a certain amount of time has elapsed (i.e. making a phone call at a specific pre-determined time, or turning the oven off after 30 minutes), whereas eventbased tasks require an action to be completed when a specific target event occurs in the 
individual's environment (i.e. completing an ongoing daily task and when you see your colleague, stopping the ongoing task and relaying a message to them; R. E. Smith, 2008). Activity-based tasks are similar to event-based in that they require a cue from the environment, however the action is to be completed after or during an activity (e.g., turning off the oven after cooking; Kvavilashvili \& Ellis, 1996). Each PM type (event-, time-, and activity-based) requires different levels of cognitive demand, dependent on the monitoring strategies used.

Many models of PM have been developed, including the Multiprocess Framework of PM (McDaniel \& Einstein, 2000), which posits that prospective remembering can occur due to either monitoring (keeping the PM task in mind and searching the environment for PM cues while completing an ongoing task) or spontaneous retrieval (spontaneously remembering to complete a PM action, as if the intention popped into mind). The more recent Dynamic Multiprocess Framework (Scullin, McDaniel, \& Shelton, 2013), on the other hand, proposes that both monitoring and spontaneous retrieval are interconnected and work together to support PM performance. This model suggests that individuals utilise strategic monitoring when environmental PM cues are expected, in time-based PM for instance, and this requires higher levels of cognitive resources for PM task completion. However, when environmental cues are not expected, generally in event- and activity-based PM tasks, individuals disengage from monitoring and instead rely on spontaneous retrieval mechanisms to support PM performance.

Intact PM skills are required to complete many everyday activities (e.g., remembering to pick up milk on the way home from work, or remembering to take medication at a certain time), thus impairments in PM functioning can have detrimental effects on the individual and those surrounding them, as well impacting the ability to 
live independently (Groot, Wilson, Evans, \& Watson, 2002). Individuals with stroke have previously been included in many studies assessing PM, when the focus has been on the broader acquired brain injury (ABI) group (Fish, Manly, Emslie, Evans, \& Wilson, 2008; Fish, Wilson, \& Manly, 2010; Groot, et al., 2002; Lemoncello, Sohlberg, Fickas, \& Prideaux, 2011), as opposed to examining the stroke population specifically. PM failure has also been identified and reviewed in other clinical and neurological populations such as schizophrenia (Ordemann, Opper, \& Davalos, 2014; Shum, Ungvari, Tang, \& Leung, 2004), traumatic brain injury (Banville \& Nolin, 2012; Canty et al., 2014; Clune-Ryberg et al., 2011; Shum, Fleming, \& Neulinger, 2002; Shum et al., 2011), mild cognitive impairment and dementia (Costa, Caltagirone, \& Carlesimo, 2011; Costa, Carlesimo, \& Caltagirone, 2012; van den Berg, Kant, \& Postma, 2006), and Parkinson’s disease (Costa et al., 2012; Kliegel, Altgassen, Hering, \& Rose, 2011; Pirogovsky, Woods, Filoteo, \& Gilbert, 2012). Of the seven reviews conducted with diverse clinical populations (outlined above), four focused on only observational measures of PM, and three reviewed both observational and intervention studies. The body of literature focusing on rehabilitative techniques to help improve PM in these populations is growing.

Localisation of PM functions within the brain has been undertaken in recent times using functional neuroimaging. These interventions have included both healthy individuals and those with brain injury (Burgess, Gonen-Yaacovi, \& Volle, 2011). The review identified the brain regions commonly involved in PM were the rostral prefrontal cortex (Rostral PFC), otherwise known as the frontal pole or Brodmann area 10 (BA10). This brain region is commonly activated during PM performance with coactivation of BA7 (precuneus) and BA40 (parietal cortex). Another region often 
associated with PM performance was the anterior cingulate cortex (ACC, BA32), however, the relation of the ACC with PM performance was not as strong as the rostral PFC or parietal regions, and therefore more research has been recommended to determine its specific role in PM functioning.

Volle, Gonen-Yaacovi, de Lacy Costello, Gilbert, and Burgess (2011) conducted a voxel based lesion study to examine both event- and time-based PM. Lesions were the result of either brain tumour or stroke and it was found that those with lesions in the BA10 showed impairments time-based PM, but not event-based PM. Given that the frontal and parietal areas of the brain are heavily involved in PM functioning, it would be expected that those with stroke, especially occurring in the anterior part of the brain would show a higher prevalence of PM deficits than those with damage to posterior regions.

\section{Purpose and Objectives}

Few studies have been conducted examining PM after stroke compared to studies related to RM and other cognitive functions. This is surprising considering PM ability is often related to daily functioning and independent living, however, given the relative infancy of research on this topic, this is understandable. The primary aim of the current paper was to summarise and critically review the limited, yet growing literature on PM following stroke to determine if PM is impaired after stroke, and whether PM interventions can improve prospective remembering post-stroke.

\section{Methods}

A scoping methodological framework (Levac, Colquhoun, \& O’Brien, 2010) was used to identify, categorise, and summarise the findings of relevant studies, as well 
as analyse the methodological quality of each study. The following review consisted of five steps: 1) identifying the research question; 2) identifying relevant studies; 3) study selection; 4) charting the data; and 5) collating, summarizing, and reporting the results. In order to guide the structure of the review strategy, a research question was formulated, 'what does existing research literature present about prospective memory performance after a stroke?' Following the practice of more contemporary reviews, the current review will also provide an analysis of methodological quality for each study. Given the limited amount of literature and varied methodological approaches assessing PM after stroke, a scoping review was considered more appropriate than a systematic review given that the aim was to broadly examine the literature on the topic. A scoping study methodology allows for the summary of previous findings, identification of gaps in the literature, and directions for future research.

\section{Identifying Relevant Studies}

The second step involved identification of relevant studies for the current review and followed two steps. First, SCOPUS, PsycINFO, and Web of Science were searched using specific terms and with the time period set from the earliest year available to April 2015 in all databases. Multiple terms for both PM (prospective memory OR memory for future intention*) and stroke (stroke OR cerebrovascular accident OR ischemia OR haemorrhage) were combined in the search to ensure no articles of relevance were missed. Second, the reference lists of the resulting articles were perused for relevant additional articles. As PM is a relatively new area of interest, one research dissertation was also included for review.

\section{Study Selection}


Potentially relevant studies were identified in the initial search. After the removal of duplicates, abstracts were reviewed using the following criteria. Studies were excluded if: (i) PM was only briefly mentioned and not directly measured or researched in studies; (ii) the samples consisted of participants with mixed aetiologies without reporting the stroke group results separately; (iii) they were either review articles or conference abstracts that examined PM in individuals with stroke; and (iv) they were written in languages other than English

\section{Data extraction, Review and Rating of Articles}

The studies that met criteria for review were then categorized into either observational or intervention studies. The observational studies were further categorised by methodology, either self-report, behavioural, or a combination of both. The studies were entered into a spreadsheet according to data including author(s), publication year, aims, research question(s), sample, measures, procedure, main findings, and limitations. Finally, analysis was performed to identify recurrent themes as well as gaps in the literature. Studies were reviewed and rated by a single rater using the STROBE statement (a 22-item scale reviewing observational studies; von Elm et al., 2007), SCED scale (an 11-item scale reviewing single-case experimental designs; Tate et al., 2008) and the PEDro-P Scale (an 11-item scale reviewing clinical trials; Murray et al., 2013), dependent on the design of the study being reviewed. These scales were chosen as they are recommended for ensuring high quality of research in populations with brain impairment (Tate \& Douglas, 2011). Effect sizes were either extracted from the studies or calculated where appropriate. Effect sizes were calculated manually and checked for

accuracy, using either Cohen's $d$, phi $(\varphi)$, and partial-eta squared $\left(\eta_{p}{ }^{2}\right)$ dependent on the statistical analysis of each study. 


\section{Results}

Of the 71 articles found, 11 studies met criteria for inclusion in the current review. Figure 1 outlines the flow of study selection. After studies were identified they were grouped into two broad categories: observational studies $(n=7)$ and intervention studies $(n=4)$.

Insert Figure 1 here

\section{Observational Studies}

All seven studies in this category utilised observational methods to measure PM performance after stroke, and were further categorised into self-report and behavioural observations (some studies utilised multiple methods of assessment and are included in both self-report and behavioural sub-categories). The methods of assessment varied, with measures used representing the different types of PM (e.g., event-, time-, and activity-based PM) and different methods for evaluating PM (e.g., self-report, behavioural, clinical, experimental measures, virtual reality (VR), etc.). The methodological quality of these studies was rated as reasonably high (i.e., ratings of 1718 out of 22) according to the STROBE checklist. The assessment used and corresponding findings, effect sizes, and quality analysis can be found in Table 1.

Insert Table 1 here 


\section{Self-report PM performance}

Five of the studies utilised self-report methods, wherein participants completed questionnaires about their everyday memory functioning. The methodological quality of these studies was rated as reasonably high (i.e., ratings of 17-18 out of 22) according to the STROBE checklist. These questionnaires resulted in a total PM score which was then compared, in some studies $(n=4)$, to scores from a control group without stroke to determine if individuals with stroke experienced more frequent PM failures. In other studies $(n=2)$, the self-reports of participants with stroke were compared with significant others' reports.

Three of the studies that compared participants with stroke to controls reported that self-reported PM failures were not significantly different between the two groups (Barr, 2011; Brooks, Rose, Potter, Jayawardena, \& Morling, 2004; Kim, Craik, Luo, \& Ween, 2009). One study however reported differing results, concluding that individuals with stroke reported significantly more PM failures than controls (Man, Yip, Lee, Fleming \& Shum, 2015). However, this finding was dependent on age, with older individuals with stroke, reporting more frequent PM failure than the younger control and older control groups. Specifically, the older-stroke group reported significantly more frequent PM failure for Basic Activities of Daily Living (BADL) than the younger-control group only and more frequent PM failure for Instrumental Activities of Daily Living (IADL) than both younger and older controls.

Two studies compared self-reported PM failure of individuals with stroke to a significant-others’ report (Barr, 2011; Man, Yip et al., 2015). Both found no significant differences between the report of significant-others and participants with stroke for total 
PM. However, when one of the studies (Man, Yip et al., 2015) examined the BADL and IADL subscales separately for both old and young stroke groups combined, a significant difference was found between scores for IADL PM, with significant-others reporting significantly more frequent PM failures for IADL (i.e. more non-routine) activities than the individuals with stroke.

\section{Behavioural measurement of PM performance}

Six of the studies utilised behavioural measures of PM. These studies either used experimental paradigms $(n=3)$, VR platforms $(n=1)$, standardised clinical measures $(n$ = 3), or naturalistic measures of PM $(n=3)$ to examine impairments in PM post-stroke, often comparing the performance of individuals with stroke to non-stroke control groups. The methodological quality of these studies was rated as reasonably high (i.e., ratings of 17-18 out of 22) according to the STROBE checklist. The behavioural measures targeted different types of PM including time-, event- or activity-based PM, or a combination reflected in a total PM score (e.g., Kim, Craik et al., 2009).

While one study measured activity-based PM (Brooks et al., 2004) finding that individuals with stroke performed significantly worse than controls, the majority focused on event- and time-based PM performance. The studies examining event-based PM resulted in mixed findings, with two of the studies reporting significantly poorer event-based PM performance for participants with stroke compared to controls (Brooks et al., 2004; Man, Chan \& Yip, 2014), and the other four reporting no significant differences between the individuals with stroke and controls (Bar, 2011; Cheng, Tian, Hu, Wang, \& Wang, 2010; Kant et al., 2014; Kim, Craik et al., 2009). Results seemed to be dependent on the type of measure used. Significant findings were found when 
utilising a VR paradigm (Brooks et al., 2004), a naturalistic task (remembering to ask for a written explanation at the end; Brooks et al., 2004), and the Cambridge Prospective Memory Task - Hong Kong Chinese Version (CAMPROMPT-HKCV; Man, Chan \& Yip, 2014). No significant differences were found when using another naturalistic task (remembering to ask for a belonging back; Brooks et al., 2004; Kant et al., 2014; Kim, Craik et al., 2009), the Virtual Week (Kim, Craik et al., 2009), the original version of the CAMPROMPT (Barr, 2011) or experimental/laboratory measures (Cheng et al., 2010; Kant et al., 2014).

Three studies examining time-based PM reported significantly poorer performance for individuals with stroke compared to controls (Cheng et al., 2010; Kim, Craik et al., 2009; Man, Chan \& Yip, 2014). Another two studies reported no significant differences between the groups’ PM performances (Barr, 2011; Brooks et al., 2004), and one reported mixed findings dependent on the measure used (Kant et al., 2014). As with the event-based PM, findings were dependent on the type of measure utilised. Significant differences were found when using the CAMPROMPT-HKCV (Man, Chan \& Yip, 2015), Virtual Week (Kim, Craik et al., 2009), and experimental/laboratory measures PM (Cheng et al., 2010; Kant et al., 2014), however no significant differences were found when utilising a VR platform (Brooks et al., 2004), the original version of the CAMPROMPT (Barr, 2011) and a naturalistic task (making a phone call after 30 minutes; Kant et al., 2014).

\section{Intervention Studies}

Four studies aimed to assess the efficacy of treatment on PM impairments in individuals with stroke. Details of the intervention studies are summarised in Table 2. A 
combination of external and internal compensatory strategy training was used by Miller and Radford (2014) to evaluate the impact of a group-based memory intervention on PM performance. While significant-others reported a significant improvement in PM after training using self-report methods, no such differences were reported by individuals with stroke. This was the only group-studied examining an intervention on PM however the methodical quality rated by the PEDro-P Scale (Murray et al., 2013) was moderate (5/11). The study was limited by the high drop-out rate, and the use of pseudo-random allocation rather than true random allocation of participants to intervention groups. It was also not clear whether both participants and assessors were blind to the condition that participants had been placed in.

Insert Table 2 here

Three studies used a single case design. Sohlberg, White, Evans and Mateer (1992b) examined Prospective Memory Training (PMT; Sohlberg, White, Evans, \& Mateer, 1992a) as a remedial technique for PM impairment in one participant poststroke. It was found that the participant's PM ability gradually increased over the course of the intervention. The methodological quality rated by the SCED scale (Tate et al., 2008) was moderate (6/11). Using external compensatory rehabilitation strategies, van den Broek, Downs, Johnson, Dayus, and Hilton (2000) evaluated an electronic memory aid for PM performance post-stroke. It was concluded that a Voice organiser (VO) device could improve PM ability after stroke; however results were highly dependent on individual differences in the two participants. The methodological quality rated by the SCED scale was moderate (7/11). Kim, Burke, Dowds, Robinson Boone, and Park 
(2000) conducted a questionnaire which assessed participants' satisfaction with a palmtop computer which aimed at improving PM performance. One single stroke participant reported that thepalmtop computer was not beneficial, primarily due to a lack of interest and prior technological experience, however the methodology of this study was rated as poor $(3 / 11)$.

\section{Other Features of the Studies $(n=11)$}

Other features which were addressed in the previous studies included time poststroke, the study setting, depression, the prevalence and neuropathology of PM impairment post-stroke, and the effect sizes. The studies included in the current review assessed the PM abilities of individuals with stroke from one week post-stroke to 47 years post-stroke, however only one study (Miller \& Radford, 2014) explored the relationship of time post-stroke to PM performance, finding that individuals who had a longer time since stroke onset showed less improvement after an intervention when PM was measured using the RPA-ProMem. The study settings also varied with two studies recruiting inpatients, six studies recruiting outpatients, and three studies recruiting community-dwelling individuals with stroke. Level of depression was only investigated by Barr (2011), who found that higher levels of depression were related to significantly poorer performance on time-based tasks.

Little is known about the prevalence of PM impairment post-stroke. One study (Kant et al., 2014) reported the prevalence of PM failure in the stroke group to be $41 \%$. This percentage suggests that PM failure is a problem for a substantial proportion of people with stroke. No other studies reported data relating the prevalence of PM impairment in the stroke samples. 
The effect sizes varied from small to large, dependent on the type of study. Majority of the effect sizes calculated for self-reported PM were small (63.2\%, $n=12$; medium $=26.3 \%, n=5$; and large $=10.5 \%, n=2)$. However, when calculated for observational measures of PM, the majority were large (50\%, $n=12$; medium $=25 \%, n$ = 6; and small $=25 \%, n=6$ ). Only two effect sizes were calculated for the intervention studies because the studies did not report enough information for them to be calculated. The effect sizes that were calculated were small and large.

Kant et al. (2014) also explored the impact of lesion location on PM performance post-stroke. It was found that lesions in the right superior temporal gyrus (STG) were more prevalent in individuals with selective PM failure (time-based or event-based, not both) in comparison to those without PM impairment. These findings however warrant further investigation as the methods used in the study to explore anatomical correlates were somewhat coarse. One observational study previously mentioned examined the impact of thalamic lesions on PM impairment post-stroke (Cheng et al., 2010). Cheng et al. (2010) concluded that individuals with thalamic lesions due to stroke had impaired time-based PM $(p<0.01)$ but not event-based PM when compared to non-stroke controls, with no differences being found between right and left thalamic lesions. Additionally, it was found that the volume of thalamic lesion was negatively correlated with time-based PM performance $(r=-0.86, p=0.000)$. Other than Kant et al. (2014) and Cheng et al. (2010), no other observational studies examined the patterns of neuropathology associated with PM impairment following stroke.

\section{Discussion}


It is apparent that the literature is limited when examining the impact stroke has on PM functioning. The investigation of PM abilities in stroke populations is a relatively new area of memory research, and more research is needed within this growing area. The literature reviewed here, while narrow, suggests that stroke has a significant impact on PM performance, specifically time-based PM, in that when measured using behavioural measures of PM, individuals with stroke often show impairments in their PM abilities compared to control groups. The majority of the effect sizes are large, suggesting a significant impairment after stroke, however it must be noted that results are mixed and variables which impact on PM and limitations of the reviewed studies need to be considered when interpreting the results.

While the rehabilitative research is limited, and three out of the four studies used single-case experimental designs, it provides avenues and directions for future PM rehabilitation. PMT training (Sohlberg, 1992a), while offering promising results for the improvement of PM post-stroke, is intensive and requires a lot of time commitment from both the client and therapist. Additionally, single case experimental designs limit the generalisation of results to wider populations and can have carry-over and order effects. While Miller and Radford's (2014) group intervention study reported a trend towards significance, no significant difference was found in PM performance after the intervention. This trend towards significance accompanied by the moderate effect size suggests that the small sample size might have been a limiting factor. The studies examining technological devices to better PM performance (Kim, Burke et al., 2000; van den Broek et al., 2000), found improvements to be highly dependent on the individuals' preference and experience with technology. Limitations aside, these studies offer broad direction for future research. More rehabilitative techniques and 
interventions need to be developed, conducted, and assessed with larger stroke samples wherein PM is assessed using reliable, standardised measures to provide more evidence for rehabilitative interventions and tools.

There are a number of possible reasons for the varied findings regarding whether PM impairment is a problem after stroke. First, different types of PM measures have different strengths and limitations. While many studies used reliable and validated selfreport measurements, such as the Prospective and Retrospective Memory Questionnaire (PRMQ; G. Smith, Del Sala, Logie, \& Maylor, 2000), Comprehensive Assessment of Prospective Memory (CAPM; Roche, Fleming, \& Shum, 2002), and the Brief Assessment of Prospective Memory (BAPM; Man, Fleming, Hohaus, \& Shum, 2011), results from self-report measures which have not been evaluated for reliability or validity may result in unreliable findings (i.e. the 10-item questionnaire used by Brooks et al., 2004). Additionally, when using validated measures it is helpful if the results for each sub-scale are reported separately. For example, Barr (2011), using the PRMQ, summed the retrospective and prospective components to form a measure of everyday memory function total. Thus, when interpreting the results in relation to PM function, there is no delineation of PM from RM failure limiting conclusions about self-reported PM post-stroke.

One possible reason as to why PM impairment was not found in individuals with stroke when using self-report methods is the sample size. While Barr (2011), Brooks et al. (2004) and Kim, Craik et al. (2009) found no such impairment, Man, Yip et al. (2015) did. These contrasting findings to previous research may have been due to the larger sample size $(n=75)$ and hence greater power, as compared to the other studies with smaller sample sizes (range $=12$ to 25). Furthermore, while self-report methods 
are easy to administer in both clinical and experimental settings, impairments in selfawareness following neurological injury can impact the reliability of the results (Roche et al., 2002). So while majority of the studies found no significant differences between the self-rating of PM for participants with stroke and controls (Barr, 2011; Brooks et al., 2004; Kim, Craik et al., 2009), this does not necessarily mean that PM is not impaired post-stroke. In fact, this method of assessment may be measuring self-awareness of PM failure rather than PM failure itself. As suggested by Barr (2011), Brooks et al. (2004), Kim, Craik et al. (2009), and Man, Yip et al. (2015) self-reports should be interpreted with caution as impairments in self-awareness are highly probable and participants with stroke may be reporting their pre rather than post-stroke abilities.

As PM performance is reliant on a multitude of cognitive functions, it is important to examine and control for any cognitive impairments participants may have to ensure a true measure of PM performance is attained. One such function is RM, where RM performance has been found to be a significant predictor of experimental event-based PM (Kant et al., 2014; Kinch \& McDonald, 2001). When comparing PM to other cognitive functions, Kant et al. (2014) found that PM failure occurred in 41\% of individuals with stroke and was significantly higher than the prevalence of impairments in processing speed, and attention/executive functioning, but not significantly different from the frequencies of RM failure. A significant limitation of this study, as well as previous studies (Man, Chan \& Yip, 2014) was not screening for RM impairment before running the experiment. Prospective remembering has both a prospective and retrospective component, and if a person cannot remember what the task is, he or she cannot be expected to perform it. 
Another cognitive function which has been said to impact on PM performance is monitoring ability, specifically time-based. While the laboratory measures of PM reviewed consistently found significant deficits in time-based PM, it is concluded that this finding may not be due to monitoring abilities, as the difference in the amount of clock checks, between participants with stroke and controls was not significant (Cheng et al., 2010; Kant et al., 2014; Kim, Craik et al., 2009). If monitoring ability is not significantly impaired after stroke, further research is needed to examine why individuals with stroke have specific difficulties with time-based tasks. It may simply be due to the belief that time-based PM tasks are believed to require more cognitive resources for completion than event-based tasks, as performance relies on higher levels of initiation, monitoring, and executive control (McDaniel \& Einstein, 2007), and often these cognitive functions are left impaired after stroke.

Many additional factors pertaining to the participants themselves, could have impacted PM performance and were not necessarily controlled for or addressed by all the studies. There was considerable heterogeneity in the stroke populations studied, in terms of time since stroke onset, stroke severity, and lesion location, and these factors are likely to impact on the presence and extent of PM impairment.

The studies included in the current review assessed the PM abilities of individuals with stroke from one week post-stroke to 47 years post-stroke. The large variation in time from 1 week to many decades post-stroke could have an impact on PM abilities in multiple ways. Neurological function starts to recover within the first few days after stroke, with rapid gains realised in the first three months, followed by slower gains in the following six to twelve months, with some individuals still showing gains one to two years post-stroke (Hankey, 2007). Thus, time since onset of stroke can 
greatly impact on the level of impairment, especially when recovery patterns differ for each individual patient (Langhorne, Bernhardt, \& Kwakkel, 2011). Not just in terms of natural recovery, but those in different stages of rehabilitation could be expected to show different results, as found by Miller and Radford (2014), who reported greater PM improvement for those who accessed rehabilitation closer to the onset of stroke. This finding is promising for researchers and clinicians working with people who have had a stroke and PM.

Study settings and an individual's opportunity to experience PM failure can also play a role in how individuals with stroke report PM impairment, particularly on selfreport measures. This is because level of independence and different testing environments may see significant-others or nurses/carer completing daily PM tasks for individuals with stroke. This could impact how participants and their significant-others self-report PM failures which focus on BADL and IADL PM.

Additionally, factors such as damage location and level of depression were not always addressed. While most studies outline the type of stroke and lateralisation, only Kim, Craik et al. (2009) reported which lobes were damaged, providing a clear outline of the location of damage to the brain. This is important as individuals with damage to brain regions not related to PM function would not be expected to show PM impairment. Level of depression was only investigated by Barr (2011), who found that higher levels of depression were related to significantly poorer performance on timebased tasks. As depression has been found to negatively impact on PM performance, it is also imperative to control for, especially as depression is quite common post-stroke (Hoffmann, Ownsworth, Eames, \& Shum, 2015). 
The methodological quality of the studies ranged from high to low, dependent on the study and measure used. Observational studies, rated using the STROBE statement resulted in a narrow range of scores. While this may suggest that the methodological quality of the observational studies was high, it is not necessarily the case. Rather, the narrow range of scores outlines the limitations of the STROBE as a quality analysis tool. This is most likely because it was primarily designed to be used more as a reporting guideline, rather than an evaluation tool (von Elm et al., 2007). The main reasons why studies were rated moderate to low in quality when using the SCED scale was because observer bias, independence of assessors, statistical analysis and evidence for generalisation were not addressed. These studies could be improved by addressing these simple factors. Additionally, the group intervention study received a moderate quality rating when assessed with the PEDro-P scale because pseudo-random allocation was used rather than random allocation. It was also not mentioned whether allocation was concealed; whether blinding of participants, therapists, and assessors took place; and there was a high level of drop out meaning that the measures of at least one key outcome were not obtained from more than $85 \%$ of the subjects initially allocated to groups. Study quality could be improved by addressing these factors and improving the rate of drop out.

\section{Limitations of the study}

This review would have been strengthened by using two raters instead of one and incorporating inter-rater reliability tests into the procedure. The evaluation of studies was also limited by the tools chosen to rate methodology. The STROBE statement was used for the purposes of evaluating methodological quality, however it generated a narrow range of scores. Thus it is recommended that future reviews utilise a 
tool which has been designed to rate the methodological quality of observational studies such as a Risk of Bias measure.

\section{Recommendations for future research}

Overall, future research should focus on using reliable and valid PM measures, control for or stratify individuals of stroke into groups based on factors which have previously been found to impact PM performance (i.e. RM performance, monitoring ability, time-since stroke onset, location of testing, location of damage to the brain, level of depression and level of self-awareness) and develop and evaluate rehabilitative techniques to help improve PM performance post-stroke. Future research could be conducted to examine the utility of other external (e.g., smart phone applications) and internal compensatory rehabilitative strategies. It is suggested that training programs take into consideration the personal preferences of individuals with stroke, specifically in relation to any technology that is introduced.

Implementation intentions (a simple goal-setting strategy) have been used previously to improve PM performance in non-stroke adult populations (Chen et al., 2015), as well as other clinical populations like early psychosis (Khoyratty et al., 2015). It is suggested that future rehabilitation research can consider utilising this simple, yet effective internal strategy to assess the effect on PM functioning post-stroke.

Overall, PM impairment exists after stroke, particularly when examined using behavioural measures. As PM is linked with abilities in everyday functioning, it is imperative that future research is conducted to help examine both the extent and nature of PM impairment after stroke. 
Financial Support

This research received no specific grant from any funding agency, commercial or notfor-profit sectors.

Conflict Of Interest

None. 


\section{References}

Andrews, G., Halford, G. S., Chappell, M., Maujean, A., \& Shum, D. (2014). Planning following stroke: a relational complexity approach using the Tower of London. Frontiers in Human Neuroscience, 8(1032), 1-14. doi:

10.3389/fnhum.2014.01032

Andrews, G., Halford, G. S., Shum, D., Maujean, A., Chappell, M., \& Birney, D. P. (2014). Verbal learning and memory following stroke. Brain Injury, 28(4), 442447. doi: 10.3109/02699052.2014.888758

Australian Institute of Health and Welfare. (2013). Stroke and its management in Australia: an update. (Cat. no. CVD 61.). Canberra: AIHW. Retrieved from http://www.aihw.gov.au/publication-detail/?id=60129543613.

Banville, F., \& Nolin, P. (2012). Using virtual reality to assess prospective memory and executive functions after traumatic brain injury. Journal of CyberTherapy and Rehabilitation, 5, 45-55. Retrieved from http://go.galegroup.com.libraryproxy.griffith.edu.au/ps/i.do?id=GALE\%7CA32 1462389\&v=2.1\&uit=r\&p=HRCA\&asid=a8cc76a4b54577c608c6d2564cb36d6 9

Barr, A. C. (2011). Prospective Memory Functioning After Stroke: A Research Portfolio. (Dissertation/Thesis), University of Edinburgh. Retrieved from https://www.era.lib.ed.ac.uk/handle/1842/6049

Brooks, B. M., Rose, F. D., Potter, J., Jayawardena, S., \& Morling, A. (2004). Assessing stroke patients’ prospective memory using virtual reality. Brain Injury, 18(4), 391-401. doi: 10.1080/02699050310001619855 
Burgess, P. W., Gonen-Yaacovi, G., \& Volle, E. (2011). Functional neuroimaging studies of prospective memory: what have we learnt so far? Neuropsychologia, 49(8), 2246-2257. doi: 10.1016/j.neuropsychologia.2011.02.014

Canty, A. L., Fleming, J., Patterson, F., Green, H. J., Man, D., \& Shum, D. (2014). Evaluation of a virtual reality prospective memory task for use with individuals with severe traumatic brain injury. Neuropsychological Rehabilitation, 24(2), 238-265. doi: 10.1080/09602011.2014.881746

Caplan, L. R. (2006). AAN Press Quality of Life Guide: Stroke. Retrieved from http://site.ebrary.com.libraryproxy.griffith.edu.au/lib/griffith/reader.action?docI $\mathrm{D}=10130864$

Chen, X., Wang, Y., Liu, L., Cui, J., Gan, M., Shum, D., \& Chan, R. C. K. (2015). The effect of implementation intention on prospective memory: a systematic and meta-analytic review. Psychiatry Research, 226, 14-22. doi: 10.1016/j.psychres.2015.01.011

Cheng, H., Tian, Y., Hu, P., Wang, J., \& Wang, K. (2010). Time-based prospective memory impairment in patients with thalamic stroke. Behavioral Neuroscience, 124, 152-158. doi: 10.1037/a0018306

Clune-Ryberg, M., Blanco-Campal, A., Carton, S., Pender, N., O'Brien, D., Phillips, J., . . Burke, T. (2011). The contribution of retrospective memory, attention and executive functions to the prospective and retrospective components of prospective memory following TBI. Brain Injury, 25(9), 819-831. doi: $10.3109 / 02699052.2011 .589790$

Cohen, J. (1988). Statistical power analysis for the behavioural sciences. ( $2^{\text {nd }}$ ed.). New Jersey: Lawrence Erlbaum. 
Costa, A., Caltagirone, C., \& Carlesimo, G. A. (2011). Prospective memory impairment in mild cognitive impairment: an analytical review. Neuropsychology Review, 21(4), 390-404. doi: 10.1007/s11065-011-9172-z

Costa, A., Carlesimo, G. A., \& Caltagirone, C. (2012). Prospective memory functioning: a new area of investigation in the clinical neuropsychology and rehabilitation of Parkinson's disease and mild cognitive impairment. Review of evidence. Neurological sciences, 33(5), 965-972. doi: 10.1007/s10072-0120935-y

De Haan, E. H., Nys, G. M., \& Van Zandvoort, M. J. (2006). Cognitive function following stroke and vascular cognitive impairment. Current Opinion in Neurology, 19(6), 559-564. doi: 10.1097/01.wco.0000247612.21235.d9

Einstein, G. O., McDaniel, M. A., Richardson, S. L., Guynn, M. J., \& Cunfer, A. R. (1995). Aging and prospective memory: examining the influences of selfinitiated retrieval processes. Journal of Experimental Psychology: Learning, Memory, and Cognition, 21(4), 996-1007. doi:10.1037/0278-7393.21.4.996

Ellis, J., \& Milne, A. (1996). Retrieval cue specificity and the realization of delayed intentions. The Quarterly Journal of Experimental Psychology, 49A(4), 862-887. doi: $10.1080 / 713755662$

Fish, J., Manly, T., Emslie, H., Evans, J. J., \& Wilson, B. A. (2008). Compensatory strategies for acquired disorders of memory and planning: Differential effects of a paging system for patients with brain injury of traumatic versus cerebrovascular aetiology. Journal of Neurology, Neurosurgery and Psychiatry, 79(8), 930-935. doi:10.1136/jnnp.2007.125203 
Fish, J., Wilson, B. A., \& Manly, T. (2010). The assessment and rehabilitation of prospective memory problems in people with neurological disorders: A review. Neuropsychological Rehabilitation, 20(2), 161-179. doi:http://dx.doi.org/10.1080/09602010903126029

Groot, Y. C. T., Wilson, B. A., Evans, J., \& Watson, P. (2002). Prospective memory functioning in people with and without brain injury. Journal of the International Neuropsychological Society, 8(5), 645-654. doi: 10.1017/S1355617702801321

Hankey, G. J. (2007). Stroke: your questions answered. New York; Edinburgh: Chuchill Livinstone.

Hoffmann, T., Ownsworth, T., Eames, S., \& Shum, D. (2015). Evaluation of brief interventions for managing depression and anxiety symptoms during early discharge period after stroke: a pilot randomized controlled trial. Topics in Stroke Rehabilitation, 22(2), 116-126. doi: 10.1179/1074935714Z.0000000030

Hu, Q. (2010). Effect size, measures of. In N. J. Salkind (Ed.), Encyclopedia of Resarch Design (pp. 408-412). Thousand Oaks, CA: SAGE Publications, Inc.

Kalashnikova, L. A., Zueva, Y. V., Pugacheva, O. V., \& Korsakova, N. K. (2005). Cognitive impairments in cerebellar infarcts. Neuroscience and Behavioral Physiology, 35(8), 773-779. doi: 10.1007/s11055-005-0123-0

Kant, N., van den Berg, E., van Zandvoort, M. J. E., Frijns, C. J. M., Kappelle, L. J., \& Postma, A. (2014). Functional correlates of prospective memory in stroke. Neuropsychologia, 60, 77-83. doi: 10.1016/j.neuropsychologia.2014.05.015 Khoyratty, N., Wang, Y., O’Gorman, J. G., Lloyd, C., Williams, P. L., Chan, R. C. K., \& Shum, D. (2015). Forming implementation intentions improves prospective 
memory in early psychosis. Psychiatry Research. doi:

10.1016/j.psychres.2015.05.101

Kim, H. J., Burke, D. T., Dowds, M. M., Robinson Boone, K. A., \& Park, G. J. (2000). Electronic memory aids for outpatient brain injury: follow-up findings. Brain Injury, 14(2), 187-196. doi: 10.1080/026990500120844

Kim, H. J., Craik, F. I. M., Luo, L., \& Ween, J. E. (2009). Impairments in prospective and retrospective memory following stroke. Neurocase, 15(2), 145-156. doi: $10.1080 / 13554790802709039$

Kinch, J., \& McDonald, S. (2001). Traumatic brain injury and prospective memory: An examination of the influences of executive functioning and retrospective memory. Brain Impairment, 2(2), 119-130. doi: 10.1375/brim.2.2.119

Kliegel, M., Altgassen, M., Hering, A., \& Rose, N. S. (2011). A process-model based approach to prospective memory impairment in Parkinson's disease.

Neuropsychologia, 49(8), 2166-2177. doi:

10.1016/j.neuropsychologia.2011.01.024

Kliegel, M., McDaniel, M. A., \& Einstein, G. O. (Eds.). (2008). Prospective memory: cognitive, neuroscience, developmental, and applied perspectives. New York: Lawrence Erlbaum Associates, Inc.

Kvavilashvili, L., \& Ellis, J. (1996). Varieties of intention: some distinctions and classifications. In M. Brandimonte, G. O. Einstein, \& M. A. McDaniel (Eds.), Prospective memory: Theory and applications (pp. 23-51). New Jersey: Lawrence Erlbaum Associates, Inc.

Kolb, B., \& Whishaw, I. Q. (2009). Fundamentals of human neuropsychology. New York: Worth Publishers. 
Langhorne, P., Bernhardt, J., \& Kwakkel, G. (2011). Stroke rehabilitation. The Lancet, 377, 1693-1702. doi: 10.1016/S0140-6736(11)60325-5

Lemoncello, R., Sohlberg, M., Fickas, S., \& Prideaux, J. (2011). A randomised controlled crossover trial evaluating Television Assisted Prompting (TAP) for adults with acquired brain injury. Neuropsychological Rehabilitation, 21(6), 825-846. Retrieved from http://www.tandfonline.com/doi/pdf/10.1080/09602011.2011.618661

Levac, D., Colquhoun, H., \& O’Brien, K. K. (2010). Scoping studies: advancing the methodology. Implementation Science, 5, 69-78. doi:10.1186/1748-5908-5-69

Lincoln, N. B., Kneebone, I. I., \& Macniven, J. A. B. (2012). Psychological management of stroke. Retrieved from http://site.ebrary.com.libraryproxy.griffith.edu.au/lib/griffith/detail.action?docID $=10526566$

Man, D. W. K, Chan, M. K. L., \& Yip, C. C. K. (2014). Validation of the Cambridge Prospective Memory Test (Hong Kong Chinese version) for people with stroke. Neuropsychological Rehabilitation, 25(6), 1-18. doi: 10.1007/s12144-006-10028

Man, D. W. K., Fleming, J., Hohaus, L., \& Shum, D. (2011). Development of the Brief Assessment of Prospective Memory (BAPM) for use with traumatic brain injury populations. Neuropsychological Rehabilitation, 21(6), 884-898. doi: $10.1080 / 09602011.2011 .627270$

Man, D., Yip, C., Lee, G., Fleming, J., \& Shum, D. (2015). Self-report prospective memory problems in people with stroke. Brain Injury, 29(3), 329-335. doi: 10.3109/02699052.2014.974672 
McDaniel, M. A., \& Einstein, G. O. (2000). Strategic and automatic processes in prospective memory retrieval: a multiprocess framework. Applied Cognitive Psychology, 14(7), s127-s144. doi: 10.1002/acp.775

McDaniel, M. A., \& Einstein, G. O. (2007). Prospective memory: an overview and synthesis of an emerging field. Thousand Oaks, Calif: SAGE Publications.

Miller, L. A., \& Radford, K. (2014). Testing the effectiveness of group-based memory rehabilitation in chronic stroke patients. Neuropsychological Rehabilitation, 24(5), 721-737. doi: 10.1080/09602011.2014.894479

Murray, E., Power, E., Togher, L., McCabe, P., Munro, N., \& Smith, K. (2013). The reliability of methodological ratings for speechBITE using the PEDro-P Scale. International Journal of Language \& Communication Disorders/Royal College of Speech \& Language Therapists, 48(3), 297-306. doi:10.1111/14606984.12007

Ordemann, G. J., Opper, J., \& Davalos, D. (2014). Prospective memory in schizophrenia: a review. Schizophrenia Research, 155, 77-89. doi: 10.1016/j.schres.2014.03.008

Pirogovsky, E., Woods, S. P., Filoteo, J. V., \& Gilbert, P. E. (2012). Prospective memory deficits are associated with poorer everyday functioning in Parkinson's disease. Journal of the International Neuropsychological Society, 18(6), 986995. doi: 10.1017/S1355617712000781

Radford, K. A., Lah, S., Say, M. J., \& Miller, L. A. (2011). Validation of a new measure of prospective memory: the Royal Prince Alfred Prospective Memory Test. The Clinical Neuropsychologist, 25, 127-140. doi: 10.1080/13854046.2010.529463 
Roche, N. L., Fleming, J. M., \& Shum, D. (2002). Self-awareness of prospective memory failure in adults with traumatic brain injury. Brain Injury, 16(11), 931945. doi: 10.1080/02699050210138581

Scullin, M. K., McDaniel, M. A., \& Shelton, J. T. (2013). The Dynamic Multiprocess Framework: evidence from prospective memory with contextual variability. Cognitive Psychology, 67, 55-71. doi: 10.1016/j.cogpsych.2013.07.001

Shum, D., Fleming, J., \& Neulinger, K. (2002). Prospective memory and traumatic brain injury: review. Brain Impairment, 3, 1-16. doi: 10.1375/brim.3.1.1

Shum, D., Levin, H., \& Chan, R. C. K. (2011). Prospective memory in patients with closed head injury: a review. Neuropsychologia, 49(8), 2156-2165. doi: $10.2340 / 16501977-0647$

Shum, D., Ungvari, G. S., Tang, W., \& Leung, J. P. (2004). Performance of schizophrenia patients on time-, event-, and activity-based prospective memory tasks. Schizophrenia Bulletin, 30(4), 693-701. doi:

10.1093/oxfordjournals.schbul.a007123

Smith, G., Del Sala, S., Logie, R. H., \& Maylor, E. A. (2000). Prospective and retrospective memory in normal ageing and dementia: a questionnaire study. Memory, 8(5), 311-321. doi: 10.1080/09658210050117735

Smith, R. E. (2008). Connecting the past and the future: attention, memory, and delayed intentions. In M. Kliegel, M. A. McDaniel, \& G. O. Einstein (Eds.), Prospective memory: cognitive, neuroscience, developmental, and applied perspectives (pp. 29-52). New York: Lawrence Erlbaum Associates, Inc. 
Sohlberg, M. M., White, O., Evans, E., \& Mateer, C. (1992a). Background and initial case studies into the effects of prospective memory training. Brain Injury, 6(2), 129-138. Retrieved from http://informahealthcare.com/

Sohlberg, M. M., White, O., Evans, E., \& Mateer, C. (1992b). An investigation of the effects of prospective memory training. Brain Injury, 6(2), 139-154. Retrieved from http://informahealthcare.com/

Tate, R. L., Mcdonald, S., Perdices, M., Togher, L., Schultz, R., \& Savage, S. (2008). Rating the methodological quality of single-subject designs and n-of-1 trials: introducing the Single-Case Experimental Design (SCED) Scale. Neuropsychological Rehabilitation, 18(4), 385-401. doi:10.1080/09602010802009201

Tate, R.L. \& Douglas, J. (2011). Use of reporting guidelines in scientific writing: PRISMA, CONSORT, STROBE, STARD and other resources. Brain Impairment, 12, 1-21. doi: http://dx.doi.org.libraryproxy.griffith.edu.au/10.1375/brim.12.1.1

Volle, E., Gonen-Yaacovi, G., de Lacy Costello, A., Gilbert, S. J., \& Burgess, P. W. (2011). The role of rostral prefrontal cortex in prospective memory: A voxelbased lesion study. Neuropsychologia, 49(8), 2185-2198. doi: 10.1016/j.neuropsychologia.2011.02.045

van den Berg, E., Kant, N., \& Postma, A. (2006). Remember to buy milk on the way home! A meta-analytic review of prospective memory in mild cognitive impairment and dementia. Journal of the International Neuropyshcological Society, 18(4), 1-11. doi: 10.1017/s1355617712000331 
van den Broek, M. D., Downes, J., Johnson, Z., Dayus, B., \& Hilton, N. (2000).

Evaluation of an electronic memory aid in the neuropsychological rehabilitation of prospective memory deficits. Brain Injury, 14(5), 455-462. doi: $10.1080 / 026990500120556$

von Elm, E., Altman, D. G., Egger, M., Pocock, S. J., Gøtzsche, P. C., Vandenbroucke, J. P., \& STROBE Initiative. (2007). Strengthening the reporting of observational studies in epidemiology (STROBE) statement: guidelines for reporting observational studies. The Lancet, 370(9596), 1453-1457. doi:10.1016/S01406736(07)61602-X

Wilson, B. A. (2005). The Cambridge Prospective Memory Test: CAMPROMPT: Harcourt Assessment.

Wilson, B. A., Cockburn, J., \& Baddeley, A. D. (1991). The Rivermead Behavioural Memory Test: Thames Valley Test Company.

World Health Organisation. (2004). The Atlas of Heart Disease and Stroke. In J. Mackay \& G. Mensah (Eds.). Switzerland: World Health Organisation 


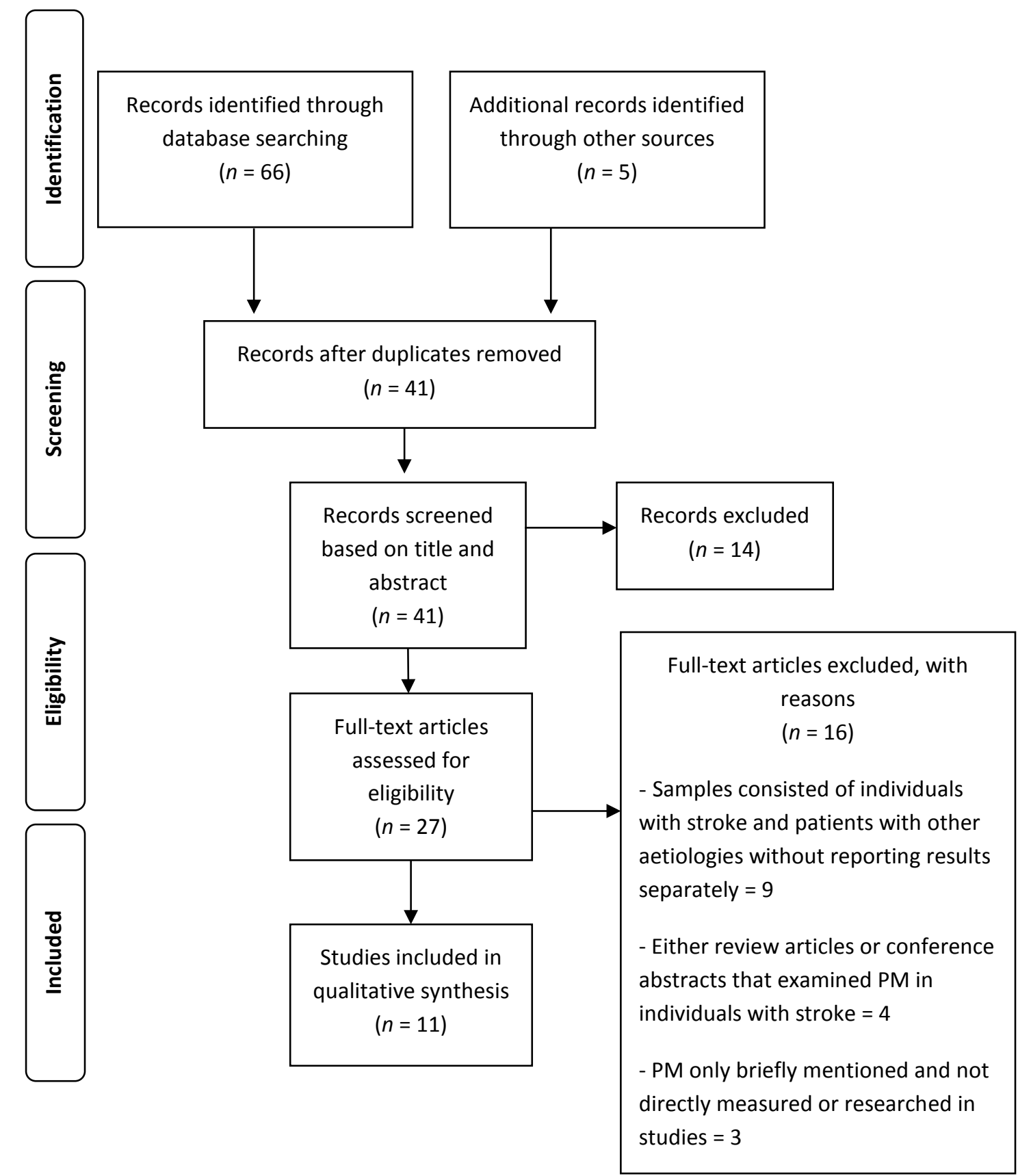

Figure 1. PRISMA flow-chart of study selection for current review

* Corresponding author: David Shum, School of Applied Psychology (Mt Gravatt Campus), Griffith University, 176 Messines Ridge Road, Mt Gravatt, Queensland, Australia 4122. E-mail: d.shum@griffith.edu.au 
Table 1

Observational Studies

\begin{tabular}{|c|c|c|c|c|c|c|c|}
\hline $\begin{array}{l}\text { Study } \\
\text { (year) }\end{array}$ & Sample & $\begin{array}{l}\text { Age in years } \\
\text { M(SD) }\end{array}$ & $\begin{array}{c}\text { Stroke } \\
\text { type/location }\end{array}$ & $\begin{array}{l}\text { Time } \\
\text { since } \\
\text { onset }\end{array}$ & Measure & Findings and effect sizes & $\begin{array}{l}\text { STROBE } \\
\text { Quality } \\
\text { Analysis } \\
\end{array}$ \\
\hline \multirow[t]{4}{*}{$\begin{array}{l}\text { Brooks et } \\
\text { al. (2004) }\end{array}$} & $\begin{array}{l}\text { 42 Stroke (inpatient; } \\
23 \mathrm{~m}, 19 \mathrm{f}) \\
\text { (17 excluded due to } \\
\text { RM deficit, thus } \\
\text { analyses based on } \\
25 \text { individuals with } \\
\text { stroke) }\end{array}$ & $71.8(9.40)$ & $\begin{array}{l}21 \mathrm{RH}, 20 \mathrm{LH}, \\
1 \mathrm{BL}\end{array}$ & $\begin{array}{l}1 \text { week - } \\
2 \text { months }\end{array}$ & $\begin{array}{l}\text { Self-report questionnaire: examining real-life } \\
\text { PM tasks. Questions included “How often do } \\
\text { you forget to take medication?” Each item was } \\
\text { answered on a seven-point Likert scale from } \\
\text { Never to Always }\end{array}$ & $\begin{array}{l}\text { Self-report PM: No significant difference between } \\
\text { stroke and matched controls ( } p=0.57 \text {, } \\
d=0.17 \text { ). }\end{array}$ & $17 / 22$ \\
\hline & $\begin{array}{l}25 \text { age-matched } \\
\text { controls }\end{array}$ & $68.44(7.11)$ & & & $\begin{array}{l}\text { Virtual Reality: Moving House Task. EBPM, } \\
\text { TBPM, and ABPM tasks, were embedded in } \\
\text { an ongoing activity wherein participants helped } \\
\text { someone move house. }\end{array}$ & $\begin{array}{l}\text { TBPM: no significant difference between stroke and } \\
\text { controls ( } p=0.05, d=-0.57 \text {; trend towards } \\
\text { significance). } \\
\text { EBPM: Controls performed significantly better than } \\
\text { stroke ( } p=0.004, d=-0.88) \\
\text { ABPM: Controls performed significantly better than } \\
\text { stroke ( } p<0.001, d=-1.06) \text {. }\end{array}$ & \\
\hline & & & & & $\begin{array}{l}\text { Naturalistic Task: Remembering a Belonging } \\
\text { task (EBPM). From the RBMT (Wilson, } \\
\text { Cockburn, \& Baddeley, 1991): participants are } \\
\text { instructed to give a personal item (i.e. a watch) } \\
\text { to the experimenter and told to remember to } \\
\text { ask for the item back at the end of the study, } \\
\text { and to recall where the item was hidden. }\end{array}$ & $\begin{array}{l}\text { EBPM: No significant difference between stroke and } \\
\text { controls }(p=1.00, \varphi=0.004) \text {. }\end{array}$ & \\
\hline & & & & & $\begin{array}{l}\text { Naturalistic Task: Written explanation task } \\
\text { (EBPM). Participants instructed to ask the } \\
\text { experimenter for a written explanation of the } \\
\text { study when they finished the VR task. }\end{array}$ & $\begin{array}{l}\text { EBPM: Control group performed significantly better } \\
\text { than stroke group }(\mathrm{p}=0.03, \varphi=0.31) \text {. }\end{array}$ & \\
\hline $\begin{array}{l}\text { Kim, } \\
\text { Craik et } \\
\text { al. (2009) }\end{array}$ & $\begin{array}{l}12 \text { stroke } \\
\text { (outpatient) }\end{array}$ & $69.33(7.02)$ & $\begin{array}{l}5 \mathrm{RH}, 5 \mathrm{LH}, 2 \\
\text { BL }\end{array}$ & $\begin{array}{l}4.8 \\
\text { months - } \\
108 \\
\text { months }\end{array}$ & $\begin{array}{l}\text { Self-report questionnaire: PRMQ (G. Smith et } \\
\text { al., 2000). 16-item self-report questionnaire } \\
\text { (eight items for each domain, PM and RM). } \\
\text { Participants rate how often each type of } \\
\text { memory failure occurs in everyday life on a } \\
\text { five-point Likert scale ranging from Never to } \\
\text { Very often. }\end{array}$ & $\begin{array}{l}\text { Total score: No significant difference for both PM } \\
\text { and RM between controls and stroke ( } p=\text { ns, } d=-0.47 \text { ). }\end{array}$ & $18 / 22$ \\
\hline & 12 age- and & $69.08(4.94)$ & & & Clinical Measure: Virtual Week (EBPM - & EBPM Regular Correct-responses: No significant & \\
\hline
\end{tabular}


education -matched

controls

Cheng et 18 Stroke (inpatient;

al. (2010)

$12 \mathrm{~m}, 6 \mathrm{f})$

18 (11 m, 7 f) ageand education-

matched controls

$\begin{array}{ll}\text { Barr } & 22 \text { Stroke } \\ \text { (2011) } & \begin{array}{l}\text { (community- } \\ \text { dwelling; 9f, 13m) }\end{array}\end{array}$

regular and irregular tasks; and TBPM.

difference between stroke and control $(p=0.44, d=-$
$0.35)$

EBPM Irregular-Correct responses: No significant difference between stroke and control $(\mathrm{p}=0.076, d=$ -

TBPM Correct-responses: Stroke significantly poorer than controls ( $\mathrm{p}=0.007, d=-1.28$ ).

EBPM Regular Miss-responses: No significant difference between stroke and control $\mathrm{p}=0.099, d=$ $0.70)$

EBPM Irregular Miss-responses: No significant difference between stroke and control $(\mathrm{p}=0.183, d=$ $0.57)$

TBPM Miss-responses: Stroke had significantly more misses than controls $(\mathrm{p}=0.001, d=1.87$ ).

Experimental Measure: Memory for Intentions (RM and Total PM). Assesses both

retrospective and prospective components of

PM through a process of associating real-life PM through a process of associating real-life
intentions to pictures and having participants intentions to pictures and having participants recall the correct

Naturalistic Task: Remembering a Belonging task (EBPM).
65 (Range $=18$ Thalamic 45-85) stroke

2 weeks -

Experimental Task: TBPM. Participants

instructed to tap desk at 5 minute intervals from the starting time (PM task) while completing an ongoing task.

\section{Experimental Task: EBPM. Participants}

instructed to tap desk when they saw an animal word during an ongoing task. Also requested to tell the experiment their phone number when the ongoing task was completed.

\section{6} haemorrhage, 7 cerebral infarction, 9 unspecified as

\section{6 months Self-report questionnaire: PRMQ}

\section{2}

RM: No significant differences between stroke and controls

PM: Stroke had significantly poorer performance on the prospective component $\left(\mathrm{p}<0.001, \eta_{\mathrm{p}}{ }^{2}=.491\right)$, even after controlling for their lower performance on the paired-associate task $\left(\mathrm{p}=0.004, \eta_{\mathrm{p}}{ }^{2}=.332\right)$.

EBPM: No significant difference found between stroke and controls $(\mathrm{p}=0.67, \varphi=0.19)$.

TBPM: Stroke performed significantly poorer than controls $(\mathrm{p}<.01, \mathrm{~d}=-2.25)$.

EBPM: No significant difference between stroke and controls ( $\mathrm{p}>.05, d=-0.46)$.

Total PM: No significant difference between control

Total PM: No significant differences between stroke and significant-other $(\mathrm{p}=0.55, d=0.10)$. 
20 significant-others

22 controls (18f,

$4 \mathrm{~m})$

Kant et 39 Strok

al. (2014) (community-

dwelling; 69\% male)

53 age-, education-

and IQ- matched

controls ( $38 \%$ male)

\section{Man, $\quad 40$ Stroke}

Chan \& $\quad$ (outpatient: 25 m, 15

$44(8 \mathrm{~m}, 36 \mathrm{f})$ controls

Man, Yip 29 younger-stroke

group (community-

(2015) dwelling; 14m, $12 \mathrm{f}$ )

\section{6 older-stroke}

group (community-

dwelling; 54m, 22f)

45.48 (3.37)

46 younger-controls

(15m, 31f)

$68.68(5.24)$

41.86 (9.32)

$49.29(5.11)$

67.07 (6.92)
19 ischemia

21

haemorrhage

1 month - Self-report questionnaire: BAPM (Man et al,

than 24

months 2011). A shortened version of the CAPM. Measures PM failure, wherein PM is broken into prospective remembering for BADL and IADL, with eight items for each, rated on a five-point Likert scale. 2005; EBPM and TBPM). Participants complete distractor puzzles as the ongoing tas and are required to complete 3 EBPM tasks and 3 TBPM tasks either throughout or after the session has ended.

Experimental measure: dual-task paradigm (EBPM and TBPM). Participants performed ongoing task pen and paper task (Bourdonamong arrays of 3-5 dots) and were required to complete both EBPM (saying 'regel' - the Dutch word for line, when whenever the last configuration in a line contained 3 dots) and TBPM (insert a coin in a designated contained after each minute had passed).

Naturalistic Task: Remembering a Belonging task (EBPM)

Naturalistic Task: Phone call (TBPM).

Participants had to make a phone call after 30 minutes

Clinical Measure: CAMPROMPT -HKCV (EBPM and TBPM). Hong Kong Chinese Version of the CAMPROMPT.
Clinical Measure: CAMPROMPT (Wilson, Wiersma task: marking arrays of four dots
Total PM: Stroke significantly more PM failure than controls $\left(\mathrm{p}<.05, \eta \mathrm{p}^{2}=.12\right)$.

EBPM: No Significant differente between stroke and control $(p>05, d=-1.53)$

TBPM: No Significant difference between stroke and control ( $\mathrm{p}>.05, \mathrm{~d}=-1.45)$. Higher levels of depression related to significantly poorer TBPM performance.

EBPM: No significant differences between stroke and $\quad$ 17/22 control ( $\mathrm{p}=0.075, \mathrm{~d}=-0.50$ ).

TBPM: Stroke significantly poorer than controls $(p=0.002, d=-0.88)$.

EBPM: No significant difference found between stroke and controls $(\mathrm{p}=0.879, d=-0.13$ )

TBPM: No significant difference between stroke and controls ( $\mathrm{p}=0.452, d=-0.23$ ).

EBPM: Stroke significantly poorer than controls $(\mathrm{p}=0.001, d=-1.34)$.

TBPM: Stroke significantly poorer than control ( $\mathrm{p}=0.001, d=-1.88)$.

PM Total Whole-group: No significant difference between stroke and significant-others ratings ( $\mathrm{p}=0.06$, $d=-0.33$; trend towards significance).

PM Total: When divided into age groups of young and old, the older-stroke group reported significantly more frequent PM failure than the young-control group $(\mathrm{p}<0.001, d=0.83)$ and the older control $(\mathrm{p}=0.01, d=0.60)$, but not the younger stroke group ( $\mathrm{p}=\mathrm{ns}, d=0.37$ ).

IADL PM Whole-group: Significant-others reported 
66 older-controls

(46m, 20f)

65 significant-others significantly more PM failures than stroke $(\mathrm{p}=0.01$, $d=-0.46$ ).

BADL PM Whole-group: No significant difference BADL PM Whole-g gup: $N$ siggificant difference 0.46 ).
between stroke and significant-other ( $\mathrm{p}=0.43, d=$ $0.46)$

IADL PM Young: No significant difference betwee stroke and significant-others ( $\mathrm{p}=0.38, d=-0.59$ ) BADL PM Young: No significant difference betwee stroke and significant-others $(\mathrm{p}=0.55, \mathrm{~d}=-0.42)$.

IADL PM Old: No significant difference between

stroke and significant-others $(\mathrm{p}=0.05, d=0.53$; trend towards significance)

IADL PM Old: Older-stroke significantly poorer than young-control ( $\mathrm{p}=0.029, d=0.89$ ), old-control $(\mathrm{p}<0.001, d=0.42)$ and young-stroke $(\mathrm{p}<0.001, d=$ $0.25)$.

BADL PM Old: No significant difference between stroke and significant-others ( $\mathrm{p}=0.39, \mathrm{~d}=0.16)$. BADL PM Old: Older-stroke significantly poor BADL PM Old: Olde-stoke significanty poorer than younger-control, $(p<0.001, d=0.72)$. No significant difference between old stroke and old control ( $\mathrm{p}=\mathrm{ns}, d=0.36$ ) or old-stroke and youngstroke ( $\mathrm{p}=\mathrm{ns}, d=0.23)$

$\mathrm{m}$ = male; $\mathrm{f}$ = female; $\mathrm{LH}$ = left hemisphere; $\mathrm{RH}$ = right hemisphere; $\mathrm{BL}$ = bilateral damage; PRMQ = Prospective and Retrospective Memory Questionnaire; CAMPROMPT = Cambridge Prospective Memory

Test; CAMPROMPT - HKCV = Cambridge Prospective Memory Test - Hong Kong Chinese Version; RPA-ProMem = Royal Prince Alfred Prospective Memory Test; BAPM = Brief Assessment of

Prospective Memory. TBPM = Time-based PM; EBPM = event-based PM; ABPM = activity-based PM. Effect sizes (Hu, 2010) measured using Cohen's $d$ are interpreted using the following criteria: 0.2;

medium $=0.5$; or large $=0.8$. Cohen (1988) suggested effect sizes be interpreted in term of small $(0.1)$, medium $(0.3)$, and large $(0.5)$ when calculated using phi $(\varphi)$, and small $(0.01)$, medium $(0.09)$, and large (0.25) when calculated using partial-eta squared $\left(\eta \mathrm{p}^{2}\right)$ 
Table 2

Intervention Studies

\begin{tabular}{|c|c|c|c|c|c|c|}
\hline $\begin{array}{l}\text { Study } \\
\text { (year) }\end{array}$ & $\begin{array}{l}\text { Stroke } \\
\text { Sample }\end{array}$ & $\begin{array}{l}\text { Age in } \\
\text { years } \\
\text { M(SD) }\end{array}$ & Stroke type & $\begin{array}{l}\text { Time } \\
\text { since } \\
\text { stroke }\end{array}$ & Design & Intervention \\
\hline $\begin{array}{l}\text { Sohlberg } \\
\text { et al. } \\
\text { (1992b) }\end{array}$ & $\begin{array}{l}\text { 1m stroke; } \\
\text { outpatient }\end{array}$ & 51 & SAH & $\begin{array}{l}15 \\
\text { months }\end{array}$ & $\begin{array}{l}\text { Single } \\
\text { case } \\
\text { ABAB }\end{array}$ & $\begin{array}{l}\text { Prospective memory } \\
\text { training (PMT). } \\
\text { Therapist systematically } \\
\text { extends the length of } \\
\text { time between PM tasks, } \\
\text { aiming to increase the } \\
\text { length of time between } \\
\text { intention formation and } \\
\text { intention execution. }\end{array}$ \\
\hline $\begin{array}{l}\text { van den } \\
\text { Broek et } \\
\text { al. (2000) }\end{array}$ & $\begin{array}{l}1 \mathrm{f}, 1 \mathrm{~m} \\
\text { stroke; } \\
\text { outpatient }\end{array}$ & 56,48 & SAH & $\begin{array}{l}19-47 \\
\text { months }\end{array}$ & $\begin{array}{l}\text { Single } \\
\text { case } \\
\text { ABA }\end{array}$ & $\begin{array}{l}\text { Electronic memory aid: } \\
\text { Voice Organiser (VO) } \\
\text { stores voice messages, } \\
\text { along with the day and } \\
\text { time when the reminder } \\
\text { is needed. When the } \\
\text { reminder is due, the } \\
\text { device sounds an alarm. } \\
\text { The message can then be } \\
\text { played by pressing a } \\
\text { button on the device. }\end{array}$ \\
\hline
\end{tabular}

button on the device.

PM measure

Quality

Time between forming an

intention and correctly

$6 / 11^{\text {a }}$

intention.

with a gradual increase throughout the study.

Experimental measure: Message-

passing task (EBPM). Relatives

needed to convey four messages

(experimenter created) to

Both participants benefited from the

introduction of the VO on the message-passing

task, as remembering was higher in the device

participants before 9:00am on

condition than both no device conditions.

pseudo-random days. Participant

required to report the message

back after 6:00pm (9 hour delay).

E.g. 'Collect the coat from the

dry cleaners.'

Experimental Measure: Domestic task (TBPM). At weekly session, experimenter gave participan

four tasks to recall to their

relatives on pseudo-random days

and predetermined times. E.g.

'Hoover the lounge at 10:00am

on Tuesday.'

Only one participant had improved

performance in the domestic task, with the

other showing deteriorated performance with the device (which may have been due to thei reliance on a written memory aid which might have been interrupted VO use).

Self-report: phone survey.

Questions discussed if the device

Kim, $\quad 1 \mathrm{f}$ stroke;

48

BL thalamic

10

Self-

Electronic memory aid -

stroke due to months report Palmtop comput

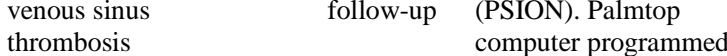

with schedule-

was useful, how often they use

it, whether they still use the

The participant patient did not consider the

device to be useful, did not purchase the

device, and yet would recommend the use of

the device to other brain-injured individuals.

management software,

their prior computer experience,

was not simiar to use the device because it 


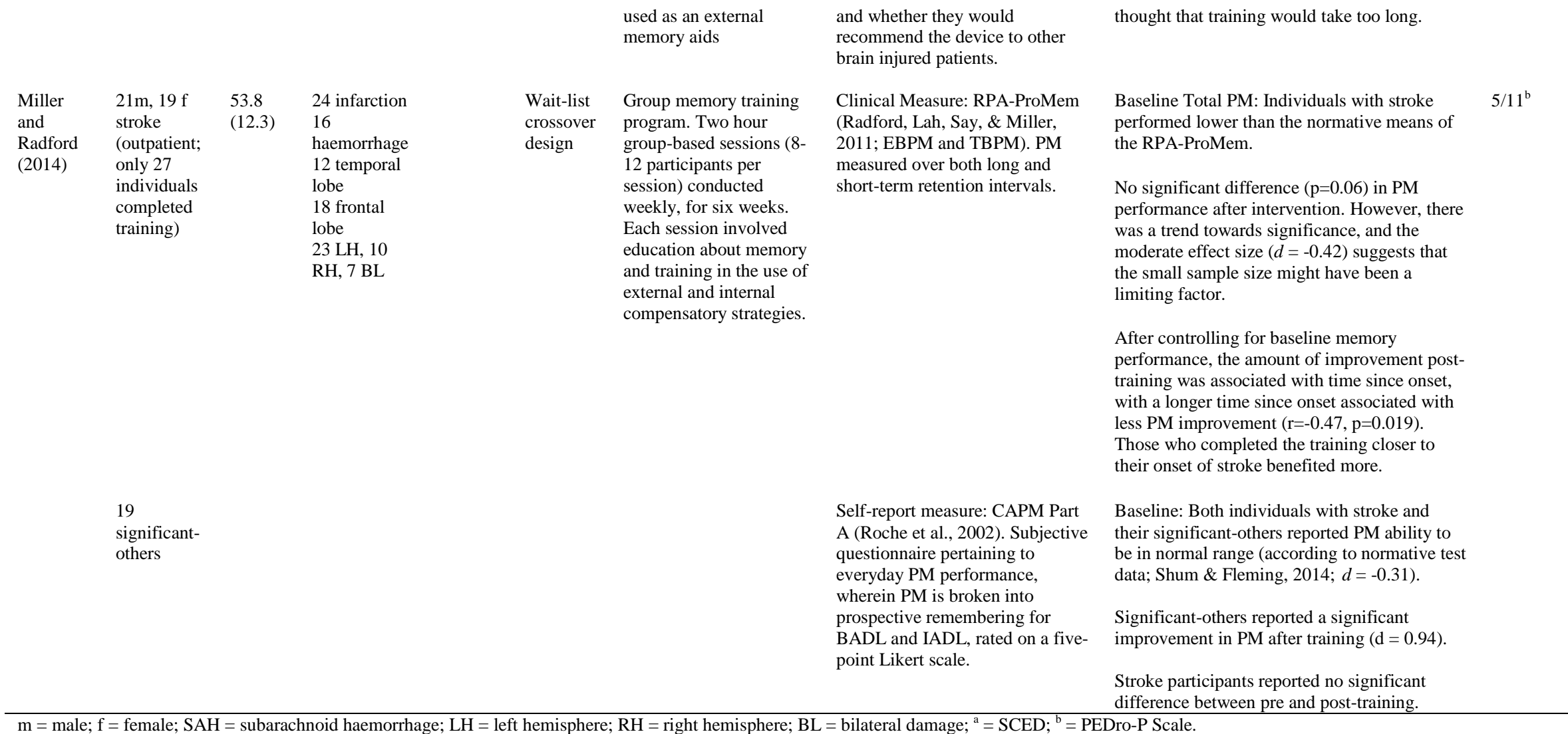

